Conclusions The GKB program has been effective in increasing booster seat use in motor vehicles for children ages 4-7 in varied school settings. These increases persisted into the following school year in a majority of the projects.

\section{FIVE YEARS OF MANDATORY BICYCLE HELMETS FOR CHILDREN IN AUSTRIA - A POST HOC EVALUATION}

Robert Bauer, Monica Steiner, Klaus Robatsch. KFV (Austrian Road Safety Board), Vienna, Austria

\subsection{6/injuryprev-2016-042156.246}

Background In Austria, bicycle helmets have been mandatory on public roads for children under 12 years of age since May 31, 2011 ( $23^{\text {rd }}$ amendment to the road safety act). The regulation was introduced as an awareness measure and is primarily designed to protect children from head injuries. Thus, there are no consequences for violation of the regulation.

Methods Post hoc evaluation of the effect of the helmet wearing legislation comprised the use of existing data sources about helmet wearing and the rate of head injuries. The main data source used for the analysis, the Injury Databases (IDB Austria), is quite unique for this purpose as it provides information on both the type of road user and the type of injury. The results on helmet wearing are based on regularly conducted counts, performed biannually since 2005 .

Results After the introduction of the regulation a significant increase of the helmet wearing rate was observed in the target group: before the introduction about $65 \%$ of children under 12 wore a helmet, by 2014 the rate was $87 \%$. This trend in helmet wearing was mirrored also in the development of the rate of head injuries of child bicyclists who were treated in hospital after an accident: before the helmets became mandatory $47 \%$ of the children under 12 years had head injuries, by 2014 the rate was $38 \%$.

Conclusions As intended by the regulation, an increase in the proportion of children wearing a helmet and a decrease in the rate of head injuries was observed. However, both trends need to be further observed in order to evaluate the supposed effect of the legislation in the long run. By the time of the Safety2016 taking place, the most recent data on both indicators will be presented in addition to results given above.

\section{KNOWLEDGE OF, ATTITUDE TOWARD AND PRACTICE OF HELMET USE AMONG MOTORCYCLE PASSENGERS IN CAMBODIA}

Kim Pagna, Chanpha Khun, Mirjam Sidik, Katherine Klaric, Bui Truong. Asia Injury Prevention Foundation

\subsection{6/injuryprev-2016-042156.247}

Background Road crashes constitute Cambodia's most serious non-communicable public health crisis, claiming on average 6 lives per day and seriously injuring 17 more. In 2014, over 70\% of victims were motorcyclists, only $12 \%$ of whom wore a helmet. AIP Foundation is implementing the USAID-DIV supported
"Head Safe. Helmet On” (HSHO) project, from 2014 to 2016 to increase helmet use, through three main components: schoolbased education, high-level advocacy, and behaviour change communications (BCC).

Methods Under BCC, a knowledge, attitude, and behaviour survey including 400 interviews in HSHO target provinces was implemented at baseline in August 2014 and at midline in August 2015. Based off of findings, BCC designs nation-wide mass media campaigns, including television and radio commercials, to address the public's stated reasons for not wearing a helmet and raise awareness on the importance of helmet use.

Results In the mid-term evaluation, most respondents (about $87 \%$ ) reported exposure to a helmet safety message in the last year. When prompted with an HSHO BCC image, $86 \%$ of respondents recalled seeing it on a TV commercial. Respondents who reported that passenger helmet use is important increased from about $45 \%$ to $60 \%$. The percentage of respondents who reported that they were likely or very likely to be stopped by police for not wearing a helmet as a passenger increased from $25 \%$ to $66 \%$. However, $67 \%$ of respondents replied that they are unlikely to be stopped by police if a child is not wearing a helmet. Awareness of the passenger helmet law, expected to be enforced in January 2016, increased from 69\% to $91 \%$. Respondents reporting that they "always" wear a helmet increased from $10 \%$ at baseline to $20 \%$ at midterm.

Conclusions $\mathrm{BBC}$ can increase public knowledge of and attitude toward the importance of motorcycle helmet use, and thereby improve citizens' practices.

\section{SYSTEMATIC REVIEW AND META-ANALYSIS OF BICYCLE HELMET EFFICACY TO MITIGATE HEAD, FACE AND NECK INJURIES}

Prudence Creighton, Jake Olivier. School of Mathematics and Statistics, University of New South Wales, Sydney, Australia

\subsection{6/injuryprev-2016-042156.248}

Background Past meta-analyses of studies assessing bicycle helmet efficacy have been criticised for poor methodology and the literature has not been systematically reviewed in over 15 years. The most recent meta-analysis reported time trend and publication biases, and found the summary odds ratio (OR) diminished when combining head, face and neck injuries. However, this study did not use standard methodology to identify biases, did not systematically review the literature, and the heterogeneity among studies reporting different injury outcomes was not assessed. The aim of this study is to systematically review and summarise results from studies assessing bicycle helmet efficacy to mitigate head, face and neck injury.

Methods Four electronic databases were searched for relevant, peer-reviewed articles in English. Included studies reported medically diagnosed head, face or neck injuries, other cycling injuries and helmet usage. Non-approved helmets were excluded where possible. Summary ORs were obtained using mixed effects models stratified by injury type and severity. Time trends were tested using cumulative models and mixed models with time as a moderator. Evidence of publication bias was assessed using funnel plot methods. 